\title{
Effect of reflow cycles on interfacial morphology of Sn-3.0Ag-0.5Cu/Cu soldered joints during solid-state aging
}

\author{
QU Min ${ }^{a}$, CAO Tian Ze ${ }^{b}$, CUI Yan ${ }^{c}$, LIU Feng Bin ${ }^{d}$, JIAO Zhi Wei ${ }^{\mathrm{e}}$, LIU Yuan ${ }^{f}$
}

School of Mechanical and Materials Engineering,

North China University of Technology, Beijing 100144, China

aminqu@ncut.edu.cn, 'blionalice@sina.com, ccuiyan@ncut.edu.cn,

dfbliu@ncut.edu.cn, ${ }^{\mathrm{e}} \mathrm{zwjjzw} @$ ncut.edu.cn, fliuyuan@ncut.edu.cn

Keywords: lead-free solder, intermetallic compound (IMC), reflow cycle, interfacial morphology, aging

Abstract. The morphology of intermetallic compounds (IMCs) at $\mathrm{Sn}-3.0 \mathrm{Ag}-0.5 \mathrm{Cu} / \mathrm{Cu}$ interface was investigated during solid-state aging with multiple reflow cycles. Results showed the scallop shape of $\mathrm{Cu}_{6} \mathrm{Sn}_{5}$ becomes elongated type with an increase in the aspect ratio gradually with increasing reflow cycles. Moreover, the thicknesses of the interfacial IMCs layer all increase linearly with the square root of aging time whatever reflow soldering cycles, and the growth kinetics equations of different reflow cycles are obtained by linear regression. It confirms that the growth of all IMCs layers follows the diffusion control mechanism. It is worth to mention that the growth coefficients increase successively with the addition of reflow cycle, indicating the IMCs layer would be thicker as increasing reflow cycles. Hence, to improve the reliability of solder joint, only one reflow cycle and proper soldering time is needed.

\section{Introduction}

As the durability and reliability of solder joints is absolutely essential to the functionality and lifespan of an electronic product, it is a key point that the solders must be optimized in terms of their physical and chemical properties to provide stable interconnections. It has long been recognized that solder joints embody a potential point of weakness in all electronic products: regardless of the ever increasing sophistication of modern electronic systems, they will not function if their component interconnections fail ${ }^{[1]}$. The $\mathrm{Sn}-\mathrm{Pb}$ has been the solder alloy system most widely used as an interconnection material in the electronic packaging industry due to the attractive combination of reliability, being well tested and cheap. However, the disadvantages of $\mathrm{Pb}$-containing solders are deadly, apart from the undeniable toxicity of lead to the human nervous system, it is also damaging to the environment in its potential for groundwater contamination ${ }^{[2]}$. Due to the toxicity of $\mathrm{Pb}$, major industrialized countries have legislated to prohibit the application of solders containing lead.

As a consequence, many lead-free solder alloys, mainly consist of Sn matrix and small additions of other elements have been proposed as the candidate solders ${ }^{[3]}$. Therefore, several $\mathrm{Pb}$-free solder alloys, including $\mathrm{Sn}-\mathrm{Zn}^{[4]}, \mathrm{Sn}-\mathrm{Sb}^{[5]}, \mathrm{Sn}-\mathrm{Cu}^{[6]}$ and $\mathrm{Sn}-\mathrm{Ag}$ alloys ${ }^{[7]}$, have received more attention. In fact, full implementation of new Pb-free solders implies a detailed knowledge and understanding of their thermodynamics, wettability, microstructure, and so on. $\mathrm{Ji}^{[8]}$ studied $\mathrm{Sn}-0.7 \mathrm{Cu}$ solder alloy by pressureless and fluxless ultrasonic-assisted die bonding, they observed that the joint consisted of sole $(\mathrm{Cu}, \mathrm{Ni})_{6} \mathrm{Sn}_{5}$ plus a thin layer of $\mathrm{Cu}_{3} \mathrm{Sn}$, and compared with transient-liquid-phase soldering, this method dramatically reduces the processing time and there was no external force acted on the dies. Spinelli ${ }^{[9]}$ investigated the interrelationship of thermal parameter, microstructure and microhardness of $\mathrm{Bi}-\mathrm{Ag}$ solder alloys by directional solidification. They reached that the hardness is directly affected by both solute macrosegregation and morphologies of the phases forming the $\mathrm{Bi}-\mathrm{Ag}$ alloys. $\mathrm{Hu}^{[10]}$ researched intermetallic compounds formations in $\mathrm{Sn} 0.7 \mathrm{Cu} / \mathrm{Cu}, \mathrm{Sn} 0.7 \mathrm{Cu} 0.7 \mathrm{Bi} / \mathrm{Cu}$ and $\mathrm{Sn} 0.7 \mathrm{Cu} 1.3 \mathrm{Bi} / \mathrm{Cu}$ solder joints during soldering at various temperatures and isothermal aging at 150 ${ }^{\circ} \mathrm{C}$. They deduced that the interfacial IMC layers are thicker with higher Bi content in solder alloy since the Bi could result in more chemical bonds between $\mathrm{Cu}$ atoms or between $\mathrm{Cu}$ and $\mathrm{Sn}$ atoms to be 
broken, which made more $\mathrm{Cu}$ and $\mathrm{Sn}$ atoms activated. Shalaby ${ }^{[11]}$ studied the effect of silver and indium addition on mechanical properties and indentation creep behavior of rapidly solidified $\mathrm{Bi}-\mathrm{Sn}$ based lead-free solder alloys, the results showed that the In and Ag containing solder alloy exhibits a good combination of higher creep resistance, good mechanical properties and lower melting temperature as compared with $\mathrm{Pb}-\mathrm{Sn}$ eutectic solder alloy.

Although numerous efforts have been made to study the interfacial reactions of $\mathrm{Pb}$-free solders with $\mathrm{Cu}$ substrate ${ }^{[12]}$, research on the interfacial kinetic reactions between the Ag-containing $\mathrm{Sn} 0.5 \mathrm{Cu}$ solders and $\mathrm{Cu}$ substrate as well as the effect of reflowing cycles on IMCs layers are still to be studied. Thus, this study focuses on the interfacial reaction and IMC growth between $\mathrm{Sn}-3.0 \mathrm{Ag}-0.5 \mathrm{Cu}$ solder and $\mathrm{Cu}$ substrate during different reflowing cycles and solid-state isothermal aging.

\section{Experimental procedures}

The commercial copper plates with dimensions of $15 \mathrm{~mm} \times 15 \mathrm{~mm} \times 3 \mathrm{~mm}$ were used as the substrates in this study. Sn-3.0 mass\%Ag-0.5 mass\% $\mathrm{Cu}$ solder paste was placed on the $\mathrm{Cu}$ substrates with a diameter of $5 \mathrm{~mm}$. Further, solder joints were formed with a F4N infrared reflow furnace. The specimens were reflowed at above liquidus temperature but the peak temperature wasn't beyond 250 ${ }^{\circ} \mathrm{C}$ for 250 s for each reflow soldering cycle, and the solder samples were reflowed one, two, three and four times, respectively.

After reflowing, the prepared solder joints were performed isothermal aging experiment in an vacuum drying oven at $150^{\circ} \mathrm{C}$ for 2 days, 4 days, 6 days, 8 days and 10days, respectively. specimens were sectioned perpendicularly to the solder/Cu interface of the solder joint and mountedThe interfacial morphologies of solder joints were observed by a Scanning Electron Microscope (SEM, ZEISS-EVO18) equipped with an Energy Dispersive X-ray Spectrometer (EDS).

Considering the reliable and repeatable data of the mean thickness of IMCs layer, three solder joints samples for each reflow cycle and aging time were used, SEM image analysis software was then employed to measure the areas of IMCs layers. The thickness of IMCs layer is determined by the area of the IMCs layer dividing its length, and the mean thickness was then calculated by averaging the data.

\section{Results and discussion}

Interfacial morphology. To reveal the effect of reflow cycle on the IMCs thickness, we researched the morphologies with different reflow cycles at the same aging time.It can be observed that the black part is $\mathrm{Cu}$ substrate in Fig 1(a-d). The white region on the top is Sn-rich phase, which is the solder matrix. Besides, some dots and coarse needle-like particles dispersed in Fig.1(a) are $\mathrm{Ag}_{3} \mathrm{Sn}$. It can be seen that the microstructure in Fig.1(a-d) is mainly composed of three parts, the white solder matrix, the black $\mathrm{Cu}$ substrate and the irregular long band-like gray layer between them.Moreover, the gray part is IMCs layer. It is clearly seen that the IMCs layer is composed of two IMC phases as shown in Fig.1(a-d), respectively. The light gray layer is $\mathrm{Cu}_{6} \mathrm{Sn}_{5}$ phase and the $\mathrm{Cu}_{3} \mathrm{Sn}$ phase correspond to dark gray layer. It is noted that with the increasing reflow cycles, the thickness of IMCs layer is increased obviously. In addition, the morphology of the IMC changed from a rounded scallop shape to an elongated scallop shape. This result is very similar to that reported by Yoon ${ }^{[13]}$.

This is mainly that the soldering reaction has taken place during liquid soldering. As solder molten, the molten $\mathrm{Sn}$ dissolves $\mathrm{Cu}$, until it is saturated. Then, the high-melting intermetallic phases start to precipitate during the molten condition due to heterogeneous nucleation and accumulate at a high rate on the $\mathrm{Cu}$ surfaces. In liquid solder and solid substrate reaction, the $\mathrm{Cu}$ flux rate going to the molten solder is low, because convection-assisted diffusion of the copper via the the liquid channel between scallop $\mathrm{Cu}_{6} \mathrm{Sn}_{5}$ into the liquid $\mathrm{Sn}$, in contrast, the transfer rate of $\mathrm{Sn}$ from the molten solder is considerably higher. As $\mathrm{Sn}$ is transformed into the metastable IMC $\mathrm{Cu}_{6} \mathrm{Sn}_{5}$, the scallop-shaped crystallites expand into the $\mathrm{Sn}$ melt ${ }^{[14]}$. With soldering time increasing, the $\mathrm{Cu}_{6} \mathrm{Sn}_{5}$ grows longitudinal to solder melt, and the scallop shape becomes elongated with an increase in the aspect ratio. 

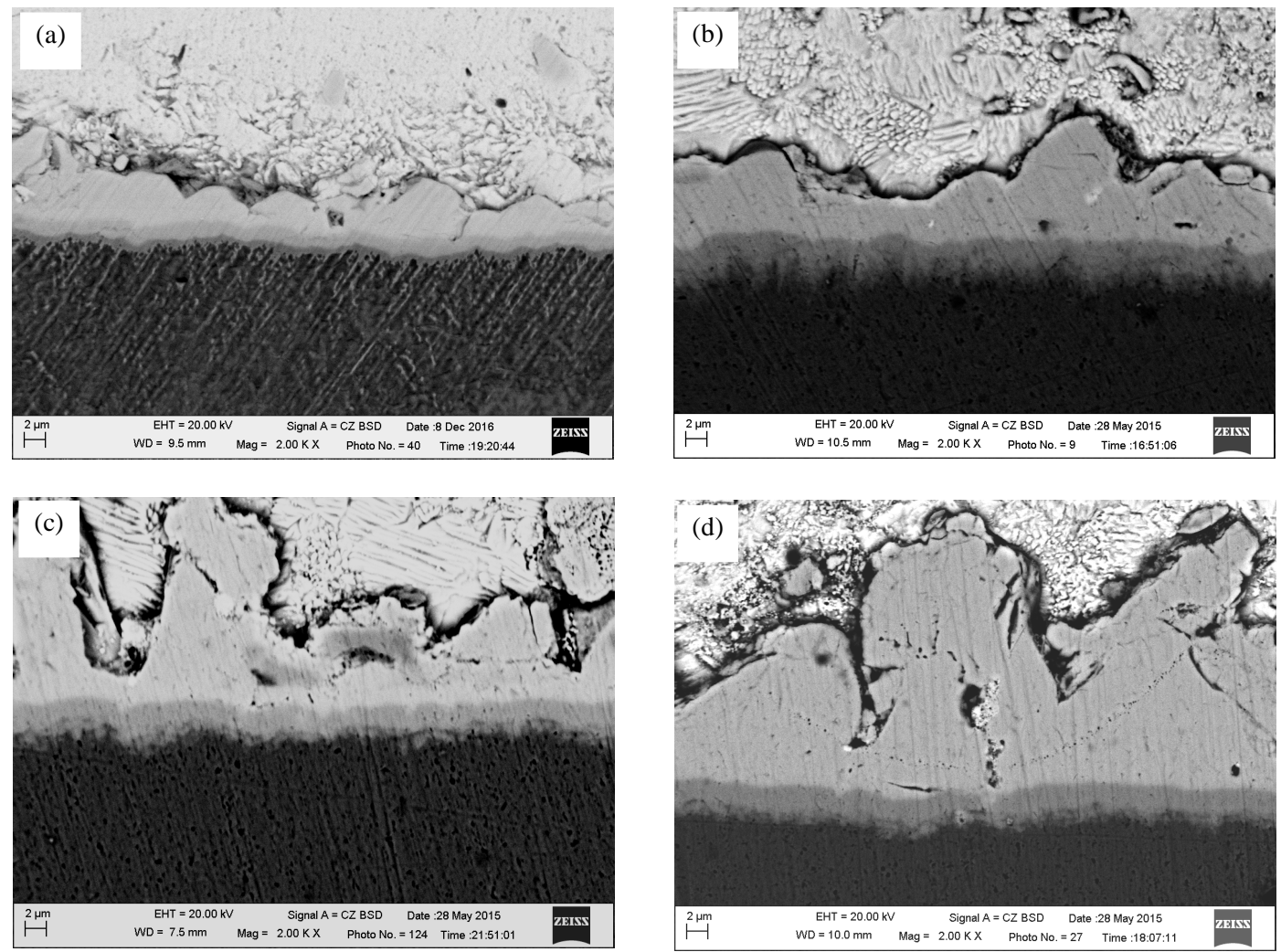

Fig. 1 The BSE images of IMC layers aged at $150^{\circ} \mathrm{C}$ for 10days during different reflow cycles: (a) one time, (b)two times, (c) three times, (d) four times.

Formation and growth behavior of IMCs layer. The formation and growth of IMCs layer consist of two processes. The first step occurs in the reflow process, where the interfacial reaction occurs at the interface between liquid solder and solid substrate. It seems that the scallop shaped $\eta-\mathrm{Cu}_{6} \mathrm{Sn}_{5}$ IMC forms at the $\mathrm{Cu}$ /liquid interface during reflow by two factors: the formation of precipitate phase due to heterogeneous nucleation, and diffusion of $\mathrm{Cu}$ atoms from the substrate into the liquid solder, the reaction occurs between the $\mathrm{Sn}$ and $\mathrm{Cu}$, proceeding as $6 \mathrm{Cu}+5 \mathrm{Sn} \rightarrow \mathrm{Cu}_{6} \mathrm{Sn}_{5}$. In addition, considering the kinetics of scallop growth, we recognize that the channels between scallop shaped $\mathrm{Cu}_{6} \mathrm{Sn}_{5}$ can serve as fast diffusion paths for $\mathrm{Cu}$ atoms to reach the molten solder ${ }^{[15]}$. However, $\mathrm{Cu}_{3} \mathrm{Sn}$ can be slightly seen after reflow without solid-state aging, the $\mathrm{Cu}_{6} \mathrm{Sn}_{5} \mathrm{IMC}$ forms first because its formation has a lower activation energy than the $\mathrm{Cu}_{3} \mathrm{Sn}$ mechanism ${ }^{[1]}$.

However, the second step occurs at the isothermal aging stage, where the interfacial reaction occurs at the interface between the solid solder and solid substrate. Also, it can be called IMC ripening. During the solid-state aging, $\mathrm{Cu}_{6} \mathrm{Sn}_{5}$ is thermodynamically unstable on the $\mathrm{Cu}$ substrate. According to thermodynamics, the driving force of the phase transformation from $\mathrm{Cu}_{6} \mathrm{Sn}_{5}$ into $\mathrm{Cu}_{3} \mathrm{Sn}$ is the decrease of Gibb's free energy ${ }^{[1]}$. As the instability increases, $\mathrm{Cu}_{6} \mathrm{Sn}_{5}$ in turn reacts with $\mathrm{Cu}$ to form the stable and planar IMC $\mathrm{Cu}_{3} \mathrm{Sn}$, proceeding as $\mathrm{Cu}_{6} \mathrm{Sn}_{5}+9 \mathrm{Cu} \rightarrow 5 \mathrm{Cu}_{3} \mathrm{Sn}$. At this stage, the diffusion of $\mathrm{Cu}$ is through the $\mathrm{Cu}_{3} \mathrm{Sn}$ layer, therefore, it will progressively be slowed down by the growing thickness of the $\varepsilon-\mathrm{Cu}_{3} \mathrm{Sn}^{[14]}$, hence, $\mathrm{Cu}_{3} \mathrm{Sn}$ layer is very thinner and grows slowly.

According to classic kinetic theory, generally, the growth of the interfacial IMCs layer is controlled by bulk diffusion at solid aging stage, and the thickness of the IMCs layer formed in the aging condition can be expressed by the simple power function.

In order to reveal the effect of aging time on the thicknesses of interfacial IMCs layer for different reflow soldering cycles, the thickness of IMCs layers were plotted against the aging time, as demonstrated in Fig. 2. It can be seen the mean thicknesses of interfacial IMCs layers were found to increase linearly with the square root of aging time whatever the reflow soldering cycles, indicating that the growth of IMCs layer with different reflow cycles all follow the diffusion control mechanism. From Fig. 2 by linear regression, it can be found that the growth trends of IMCs are consistent for different reflow cycles. For one reflow cycle, the thickness of IMCs layer follows: 


$$
X=0.74+1.97 t^{1 / 2}
$$

For two reflow cycles, the thickness of IMC layer follows:

$$
X=1.45+2.03 t^{1 / 2}
$$

And for reflowing three times, it follows:

$$
X=2.51+2.52 t^{1 / 2}
$$

For reflowing four times, it is like this:

$$
X=4.45+3.74 t^{1 / 2}
$$

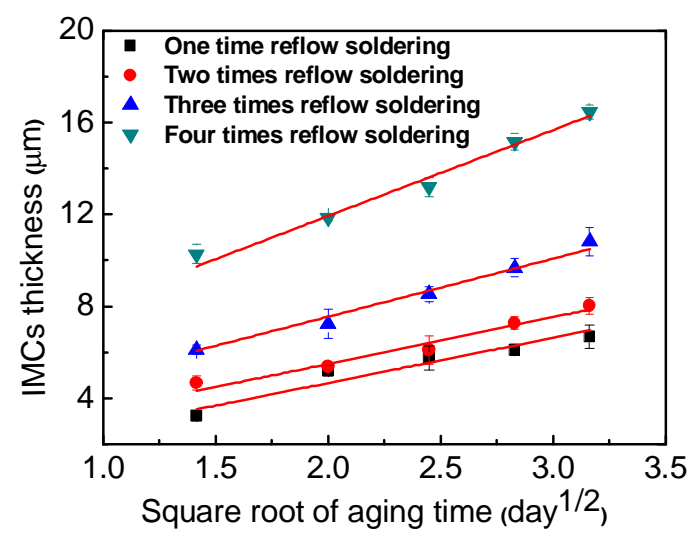

Fig. 2 IMCs thickness of $\mathrm{Sn}-3.0 \mathrm{Ag}-0.5 \mathrm{Cu} / \mathrm{Cu}$ joints with different reflow cycles.

Clearly, it can be seen that the difference among these equations are both intercept and slope. Obviously, intercepts increase successively from Eq.(1) to Eq.(4), which infers that the thickness of IMCs layer is increasing after reflow with different reflow cycles. However, the slopes, a constant about growth coefficient, increase successively from Eq.(1) to Eq.(4), too. Most importantly, it is indicated that the IMCs layer will grow fast with the increasing reflow cycles. In other words, when increasing reflow cycles, no matter the original thickness of IMCs layer after reflow treatment, the growth trend of IMCs layer is faster. Hence, we can draw the conclusion that besides solderingtemperature, aging time and temperature, the reflow cycle significantly affects the thickness of IMCs layer. Unfortunately, the thicker IMCs layer is detrimental to the reliability of solder joint. Hence, it isconcluded that only one reflow cycle is needed, and the reflow time should be proper to ensure the reliability of solder joint, consequently, the lifespan of electronic device can probably be enhanced because the failure of solder joint is the one of the key points to the reliability of integrated circuit.

\section{Conclusions}

The formation of the intermetallic compound at $\mathrm{Sn}-3.0 \mathrm{Ag}-0.5 \mathrm{Cu}$ solder/Cu interface was explored during solid-state aging with multiple reflow cycles. It is found that after different reflow soldering cycles, i.e, one cycle, two cycles, three cycles and four cycles, the morphology of $\mathrm{Cu}_{6} \mathrm{Sn}_{5} \mathrm{changes}$ from a rounded scallop shape to an elongated scallop shape. During solid state aging, the thicknesses of IMCs layer increase all linearly with the square root of aging time whatever the reflow cycles, indicating that the growth of IMCs layer follow diffusion control mechanism. What's more, the growth coefficients increase successively with increasing reflow cycles. This illustrated that the IMCs layer would be thicker as the reflow cycles increased without considering the initial thickness. Hence, to enhance the reliability of solder joint, only one reflow cycle is needed and the reflow time should be proper.

\section{Acknowledgments}

The authors would like to acknowledge the financial support provided by National Natural Science Foundation of China (NSFC) under grant No. 51604012 and 51575004, Foundation of Beijing outstanding talent training under grant No.2014000020124G010, and Natural Science Foundation of Beijing (NSFB) under grant No.3162010. 


\section{References}

[1] H. R.Kotadia, P.D. Howes and S. H. MANNAN:Micro. Reliab. Vol. 54 (2014),p.1253

[2] F.P.Mccluskey, M.Mash, Z.Wang and D.Huff: Micro. Reliab. Vol. 46 (2006), p.1910

[3] J.W. Yoon, J. H.Bang, C.W. Lee and S.B. Jung: J. Alloys Comp. Vol. 627(2015), p.276

[4] C.Y. Liu, M.H. Hon, M.C. Wang, Y. R. Chen, K.M. Chang and W.L.Li: J. Alloys Comp. Vol. 582(2014), p.229

[5] A.A. El-Daly, A.Z.Mohamad, A. Fawzy and A.M.El-Taher: Mater. Sci. Eng. A Vol. 528(2011), p. 1055

[6] A.A. El-Daly and A.E. Hammad: Mater. Design Vol. 40 (2012), p.292

[7] H.L. Li, R.An, C.Q.Wang, Y.H.Tian and Z. Jiang: Mater. Lett. Vol. 144 (2015), p. 97

[8] H.J. Ji, Y.F.Qiao and M.Y.Li: Scrip. Mater. Vol. 110 (2016), p. 19

[9] J.E. Spinelli, B.L. Silva, N. Cheung and A.Garcia: Mater. Charac. Vol. 96 (2014), p. 115

[10] X.W. Hu, Y.L. Li and Z.X. Min: J. Alloys Comp. Vol. 625(2015), p. 241

[11] R.M. Shalaby: Mater. Sci. Eng. A Vol. 560(2013), p. 86

[12] Y.Li and Y.C. Chan: J. Alloys Comp. Vol. 645(2015), p. 566

[13] J.W.Yoon and S.B. Jung: J. Alloys Comp. Vol. 396(2005), p. 122

[14] A. Munding, H. Hübner, A. Kaiser, S.Penka, P. Benkart and E. Kohn: DOI: 10.1007/978-0 $-387-76534-1-7$.

[15] K.N. Tu: Mater. Chem. Phy. Vol. 46(1996), p. 217 